\title{
Optimal Design and Practice of the Construction Scheme for Laying the Whole Track Bed on the Subway Ballastless Track
}

\author{
Chen Hui ${ }^{1}$, Qi zhenfang ${ }^{2}$ \\ ${ }^{1}$ Surveying and Mapping Engineering Department, Yellow River Conservancy Technical Institute, Kaifeng, Henan, 475001, China \\ ${ }^{2}$ Bone Surgery Department, Hui Hospital, Kaifeng, Henan, 475000, China
}

\begin{abstract}
In the development of modern society, our country attaches more importance to the development of the construction industry, and strengthens the supervision, so that the construction industry can be developed to the mode of industrialization. That combining with the construction needs of prefabricated concrete assembly in our country and taking comprehensive analysis of various factors and application, can enhance the structural stability and safety of prefabricated concrete assembly, thus can meet the needs of the modern building industrialization development, and improve the overall quality and efficiency. In the development of subway transportation field, laying the whole track bed of Ballastless track is an important core work, which is the new construction of rail transit. This paper made perfect management system, carried out all kinds of work, improved the construction technology of the whole track bed and perfected the construction plan, with the result of prolonging the service life of the subway ballastless track and promoting the stable development of modern society in our country.
\end{abstract}

\section{Introduction}

With the rapid development of economy and society in our country, the construction of modern city has been strengthened, therefor the quality of life of people has been improved, while the economic level of people has been promoted and the number of urban motor vehicles has been increased, but the pollution to the environment has been aggravated, resulting in serious urban road congestion and other problems. Therefor, increasing the construction of urban rail transit can combine the development of modern cities, can take all aspects and multi-angle analysis and can effectively solve environmental pollution, urban traffic congestion and other problems. And in the process of subway track construction, ballastless track integral track bed is an important core work. It not only higher requirements are put forward for construction technology and construction personnel, but also the design of the whole project is needed to pay attention to. The scientific design for the construction plan is needed to provide important construction basis for the following application work. In the research of this paper, three-span continuous box girder with variable section is adopted in the design of a bridge in a certain area, and the assembly prestressed concrete simply supported T-beam is used as the research sample in the treatment of side span, so as to analyze the optimal design of the construction scheme of the whole road bed laid by the subway ballastless track.

\section{Construction Difficulty of Track Bed for Subway Ballastless Track}

Compared with some developed countries, the construction technology of ballastless track bed in China has a great improvement space and value though having a later start. Our country and related departments have increased their research and strengthened the detailed understanding of the characteristics about prefabricated board track, switch board track and so on, as well as mastering the overall construction structure and introducing advanced technology and equipment so as to continuously optimize its construction plan and innovate the construction method[1], instead of blindly following the technology of high-speed railway. Based on the actual situation of the subway ballastless track, the concrete conditions and problems are analyzed in detail, while the design of the construction scheme is strengthened and the matching construction technology is researched and developed.

In the construction of the subway ballastless whole track bed, it will be affected by many factors, which will hinder its development and application. The standard construction plan is considered and civilized construction is needed as well. However, the concrete pouring of the road bed will occupy a large area of the construction main road, which will have a negative impact on the traffic and development of the modern city[2].The most effective way is to adopt the precast slab track, which can effectively solve the problems existing in the construction of the ballastless track bed. It is an

\footnotetext{
*Corresponding author's e-mail: 1400167862@qq.com, chenhuii_521@sina.com
} 
important basis for carrying out the project to perfect the construction plan, and it is necessary to work out the corresponding plan in advance according to the construction needs.

The slab track of high-speed railway is widely used in the development of China, but there are also some shortcomings, which is that the whole technology has the value of promotion. If this method is applied to the construction of ballastless track for the whole track bed, there will be a huge difference with the high-speed railway. In the process of construction and application, there are more influenced factors and worse environment of site construction, and the construction technology of slab track of high-speed railway cannot be applied directly, which is also the most important problem to be solved in the construction of subway ballastless track for the whole track bed. Therefore, it is necessary to improve and perfect the construction plan continuously for laying the whole track bed of the subway ballastless track, so as to provide the important information basis for the application and development of the following work [3].

\section{Construction Process of the Whole Track Bed for Subway Ballastless Track}

First of all, the problem to be considered is the prefabrication of track panels. These necessary specifications, quantity and so on will be ascertained based on the construction standards and carried out mass production by the professional processing enterprises. The transportation is also taken into account after production, in general, a flat car is to be used. It is necessary to reasonably select the storage base before the transportation on site and a well-positioned and rich open space can be selected if conditions are permitted. After transportation to the site, the track slab laying simulation test will be taken firstly. Choose four paving boards, which two are required to be straight line shaped and two are curved, while installation and commissioning of panels is taken by professionals, which is so-called panel adjustment experiment [4]. When the experiment is completed and fully conforms to the construction standards and requirements, objectivity summarizes of the paving process as well as reasonably plans will be made for the main line. Secondly, the 10t gantry crane is selected to hoist it, as well as the feed opening to be selected, all of which is hoisted into the flat car in the tunnel, and then transported to the specific track slab laying position by the rail flat car. Finally, it is to lay the track slab after all the work is ready to be completed. In the process of laying, all the work is required to be strictly in accordance with the relevant standards and regulations to avoid adverse impact on the following work.It is necessary to use modern equipment to fine tune the track slab after laying. All the fine adjustment results are in accordance with the relevant standards and the installation of the inner sleeve vibration isolator is required before the laying of the track slab has been completed. Then it is necessary to install the selfcompacting concrete sealing template, clamp device for prefabricated ordinary slab tracks after the fine adjustment and pour concrete in time to ensure all the gaps are filled [5]. As the laying work is done, the track laying and welding is to be carried out according to the project construction sequence and finally the quality inspection and acceptance of the whole project will be carried out.

\section{Optimization Design of the Construction Scheme for the Whole Track Bed of the Subway Ballastless Track}

To strengthen the construction management, the comprehensive analysis should be made combined with the project actual situation and a sound management system should be set to ensure the full implementation of the work. The progress of construction should be understood and controlled in detail according to the construction plan, while the construction standards of each stage should be fully mastered, as well as the supervision of the construction site should be strengthened and all work are required strictly in accordance with the construction plan. 


\subsection{Construction Plan}

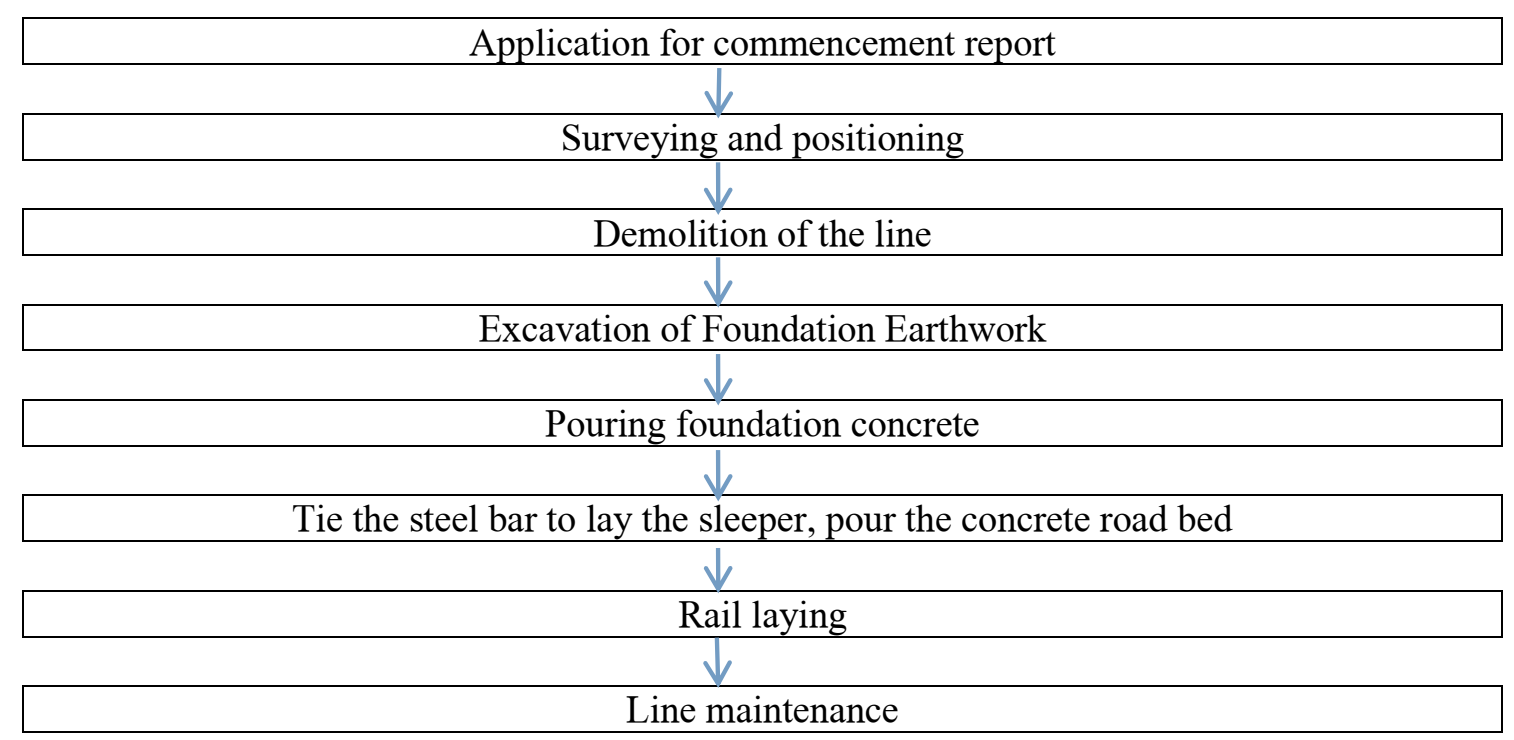

Figure 1. The Procedure of the Construction Plan

\subsection{Process Flow}

\subsubsection{Track bed Foundation}

For the application of construction technology to track bed foundation, the relevant constructors are required to understand and master the project construction situation and standards in detail prior to the excavation. In the application of the process, the constructors will take into account the underground cables, pipes, etc. Only if no cables or pipes underground are confirmed can the excavation work be done [6]. The most important equipment is the shield machine during the excavation work. Just pay attention to the height of the foundation on both sides in the process of construction, which cannot be out of bounds to avoid the adverse effects on the stability of the platform and lines on both sides. Excavation work needs to be carried out in sections, in general, 3:7 soil tamping will be required, while cushion thickness is controlled in about $0.3 \mathrm{~m}$ to be strictly according to the construction drawings as well as comprehensive analysis of the existing factors and formulating corresponding solutions in advance to avoid the occurrence of emergencies which can hinder the project construction.

\subsubsection{Steel Bar Works}

Identify the type and mesh spacing of each steel bar, which can be numbered and marked in binding according to the construction plan standard. In the binding process, the constructor may proceed according to the numbering order, which can not only reduce the difficulty of construction, but also improve the construction efficiency of steel bar binding, so as to ensure the overall stability and safety of the whole project [7].

\subsubsection{Template Engineering}

For the application of the template engineering, the most major core work is to ensure its own strength and stability. The correct construction is carried out according to the design specific requirements. In the template construction, it is necessary to paint a layer of parting agent on its surface. The purpose is to make the tight connection between each template and avoid seams, which is also the treatment of the seam filling. The handling of each detail is ensured according to the requirements of template engineering construction to ensure that the template joints do not produce leakage of cement mortar. After the template connection is completed, the template bracket is firmly handled and the selection of commercial concrete with stronger strength and tolerance pouring can produce side impact.

\subsubsection{Track bed Concrete Pouring}

For the concrete pouring of the track bed, it is necessary for the relevant constructor to master the construction process in detail and carry out it in turn. At the same time, there are strict requirements and standards for the track bed concrete pouring, especially the location of elevation line. the application scheme of subsection stratification is needed in order to find the specific location accurately. In general, the distance of 10 meters is taken as the spacing distance, and the concrete pouring of track bed is taken every 10 meters interval [8]. Take the central line position as the center and gradually carry on the construction to the marking position on two sides. It is important to note for the track bed concrete pouring that the middle is ensured to has the same height with both sides. 


\subsubsection{Completion Treatment}

With the completion of the track bed site construction of subway ballastless track, relevant personnel are needed to be able to carry out the construction site cleaning, especially the location of rail, track bed and so on to ensure the cleaning and without sundry. Increase the cleaning of fasteners, rails and drains. The most convenient way to clean up is the direct flushing with pipe pressure, which can not only improve the efficiency of the completion treatment, but also ensure each clean and tidy location.

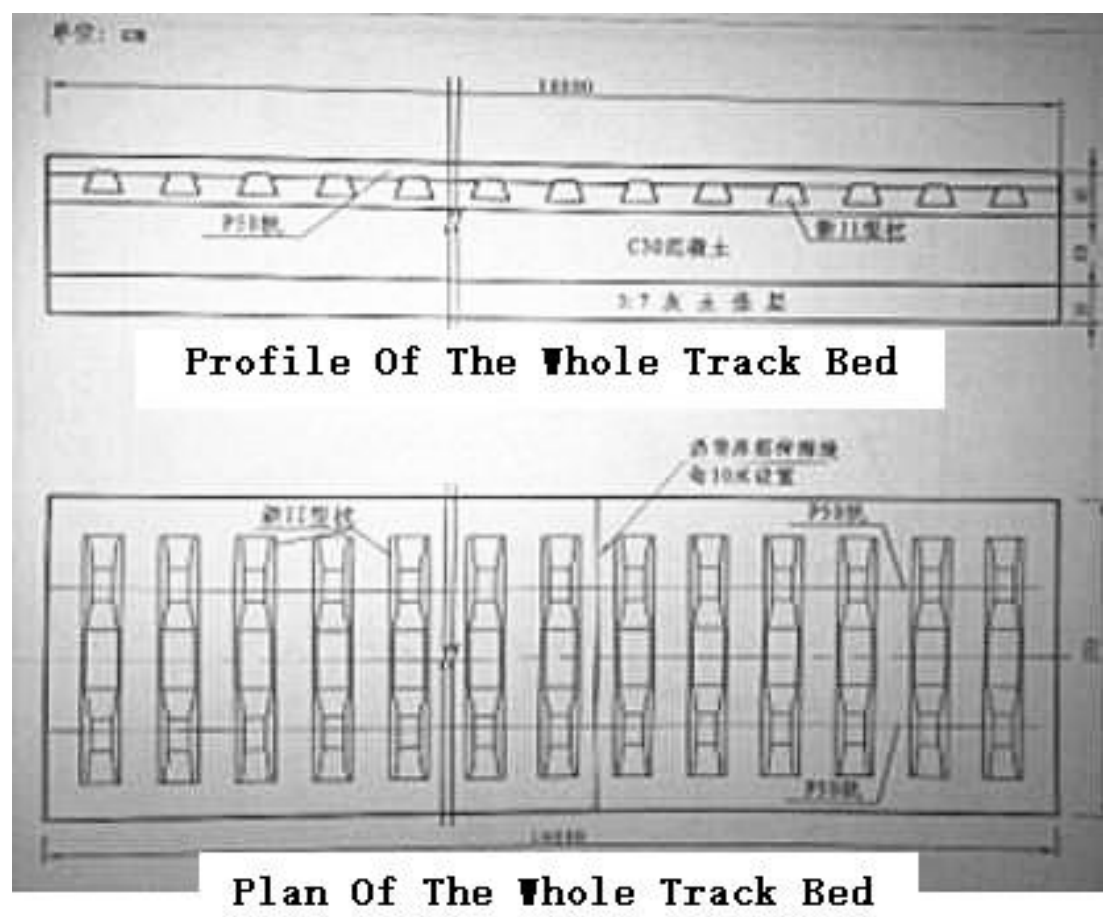

Figure 2. The Profile and Plan of the Whole Track Bed for Subway Ballastless Track

\section{Strengthen the Control of The Construction Quality of the Whole Ballastless Track Bed}

For the quality construction of the subway ballastless track for the whole track bed, it is mainly based on the construction plan and related management system. In the application process, all work is required strictly in accordance with the standard system and the construction operation process should be clear. Specify division of work content and responsibilities and put the concrete work content into each department and the personnel so that departments and personnel can work with goals, and fulfill their duties, conscientious and responsible attitude to fully comply with the relevant standards in their own work. Give reasonable arrangement of professional construction personnel, description specific key points of work and application goal so as to enable the personnel play their important role in the suitable position and strengthen the construction quality control and management of the subway ballastless track while improving the overall technical level and efficiency of construction [9]. In addition, that strengthening the management of site construction safety, carrying out safety education to the constructors, requiring the constructors to firmly establish the sense of safety first, taking every-day safety training before commencement and making detailed report against the work content, construction progress and encountered work difficulties, can continuously optimize the construction plan as there are actively discussions in various departments, which can not only effectively solve the various problems in the construction process, but also promote the positive communication between departments to ensure the overall development of the work.

Strengthen the management of the construction site and the relevant supervision departments should go to the site to check the the staff for the construction standards, equipment application safety and other detailed inspection, which can find the corresponding problems in time. If the personnel construction is not standard, it is to be corrected in time, and professional and technical education is carried out to improve the comprehensive ability of the constructor. If it is the equipment failure problem, stop working in time to rectify. Only when the equipment is in a stable state can the construction be continued. And it is necessary to carry on the comprehensive inspection to the construction project of the whole track of the subway ballastless track after the completion of the project construction to ensure the compliance with MTR standards regulation, so that it can be formally put into use while laying a good foundation for the development of modern society and cities. 
Table 1. Detailed Table of the Subway Whole Ballast Track Laying Construction Supervision

\begin{tabular}{|c|c|c|c|c|c|c|c|c|c|}
\hline \multirow{2}{*}{ NO. } & \multirow{2}{*}{$\begin{array}{l}\text { Product } \\
\text { Specifica } \\
\text { tions }\end{array}$} & \multirow{2}{*}{ Manufacturer } & \multirow{2}{*}{$\begin{array}{l}\text { Construction } \\
\text { Organization }\end{array}$} & \multirow{2}{*}{$\begin{array}{l}\text { Sampling } \\
\text { Site }\end{array}$} & \multirow{2}{*}{$\begin{array}{c}\text { Supervised } \\
\text { Population } \\
\text { Number } \\
\text { (Block) }\end{array}$} & \multirow{2}{*}{$\begin{array}{l}\text { Sample } \\
\text { Size } \\
\text { (Batch) }\end{array}$} & \multicolumn{2}{|c|}{$\begin{array}{c}\text { According to JT/T 4-2004 } \\
\text { standard }\end{array}$} & \multirow{2}{*}{$\begin{array}{c}\text { Rectification } \\
\text { Measures }\end{array}$} \\
\hline & & & & & & & $\begin{array}{c}\text { Batch } \\
\text { Qualification }\end{array}$ & $\begin{array}{l}\text { Disqualifi } \\
\text { cation }\end{array}$ & \\
\hline 1 & $\begin{array}{c}\text { GYZF } \\
350 \times 16\end{array}$ & $\begin{array}{l}\text { Cheng Du } \\
\text { Machinery } \\
\text { co. LTD }\end{array}$ & $\begin{array}{c}\text { Shanghai } \\
\text { Municipal } \\
\text { Engineering } \\
\text { co. LTD }\end{array}$ & $\begin{array}{l}\text { Nan Chang } \\
\text { A3 Standard } \\
\text { Warehouse }\end{array}$ & 16 & 1 & Qualified & / & l \\
\hline 2 & $\begin{array}{c}\text { GYZF } \\
200 \times 65\end{array}$ & $\begin{array}{l}\text { Si Chuan } \\
\text { Residential } \\
\text { Construction } \\
\text { Leasing } \\
\text { co. LTD }\end{array}$ & $\begin{array}{c}\text { Luoyang } \\
\text { engineering } \\
\text { co. LTD }\end{array}$ & $\begin{array}{c}\text { Lan Zhou } 11 \\
\text { Standard } \\
\text { Warehouse }\end{array}$ & 103 & 1 & Unqualified & $\begin{array}{c}\text { Elastic } \\
\text { mass } \\
\text { Under } \\
\text { Pressure }\end{array}$ & $\begin{array}{l}\text { Rectified and } \\
\text { Qualified }\end{array}$ \\
\hline 3 & $\begin{array}{c}\text { GYZF } \\
300 \times 65\end{array}$ & $\begin{array}{l}\text { Heng Shui } \\
\text { Engineering } \\
\text { Construction } \\
\text { co. LTD }\end{array}$ & $\begin{array}{c}\text { Fujian } \\
\text { Highway } \\
\text { Engineering } \\
\text { Company }\end{array}$ & $\begin{array}{c}\text { Gui Zhou } 14 \\
\text { Standard } \\
\text { Warehouse }\end{array}$ & 91 & 1 & Qualified & l & l \\
\hline 4 & $\begin{array}{c}\text { GYZF } \\
275 \times 65\end{array}$ & $\begin{array}{c}\text { Heng Shui } \\
\text { Rubber General } \\
\text { Factory Co. Ltd }\end{array}$ & $\begin{array}{c}\text { Shen Yang } \\
\text { Highway } \\
\text { Engineering } \\
\text { Company }\end{array}$ & $\begin{array}{c}\text { Gui Zhou } \\
\text { No.2 Beam } \\
\text { Yard }\end{array}$ & 64 & 1 & Unqualified & $\begin{array}{l}\text { Inner } \\
\text { Quality }\end{array}$ & $\begin{array}{l}\text { Rectified and } \\
\text { Qualified }\end{array}$ \\
\hline
\end{tabular}

\section{$6 \quad$ The Construction Practice Application Effect of Laying the Whole Track Bed for the Subway Ballastless Track}

Ensure the rationality of the construction plan through optimizing and designing the construction scheme of track bed for subway ballastless track. There are clear requirements for the construction of all work, the specific work content and responsibilities are clearly divided, all work is carried out strictly according to the construction plan so as to improve the overall quality and efficiency of the project and promote the stable development of subway rail transit in China[10]. Furthermore, management of the whole track bed for the subway ballastless track should be strengthened and the perfect management system should be formulated, which can not only extend the service life of the subway ballastless track, but also improve the important information basis for similar projects.

It can extend rail using Life through strengthening the rail management and maintenance. However, there are many factors that affect the rail service life. Thus it is necessary to consider the specific factors and take scientific and reasonable solutions to strengthen the rail protection. For example, it has a strong corrode to load material sulfur sand, which will cause certain corrosion to the rail if there is a long time contacting and affect the quality of the rail. The rail bottom and rail waist should be paid special attention to. It can avoid corrosion to the rail and prolong the equipment service life if reducing the direct contact of the loading material sulfur sand. The application of the subway ballastless track can meet the development needs of modern society and effectively solve the problem of urban traffic congestion, as well as reducing urban vehicles and the pollution to the environment, so as to create the good living environment for people.

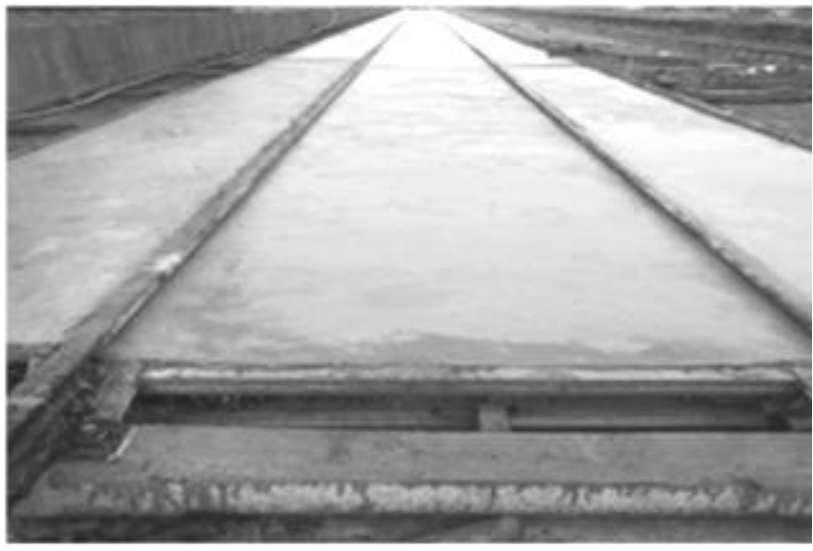

Figure 3. Construction of Track Bed for Subway Ballastless Track Effect Chart

In the design of a bridge in a certain area, three-span continuous box girder with variable section is adopted and the radius of the three spans is $45 \mathrm{~m}, 60 \mathrm{~m}$ and $45 \mathrm{~m}$ respectively. In the treatment of the side span, assembly prestressed concrete simply supported T-beam is adopted. The width is set at about $2 \mathrm{~m}$. The cantilever width on both sides of the box girder is $2.5 \mathrm{~m}$, and the width of the box girder bottom plate is above $7 \mathrm{~m}$.The longitudinal slope of the bridge is basically $2.5 \%$, while the transverse slope of the bridge is about $2.2 \%$ in the design stage. In the construction of bridge abutments, U-shaped buildings are used, which can effectively disperse and bear the weight and bridge piers and abutments can be connected stably. Double columns are used for the piers, and concrete is used in the construction to form them to ensure that the stability and durability of the bridge body $.2 .5 \mathrm{~m}$ section was used in the design of the top of the bridge pier with a height of about $4 \mathrm{~m}$.

The calculation formula of first-grade subway load is as follows, the standard value of evenly distributed load is $\mathrm{Qk}=10.5 \mathrm{kN} / \mathrm{m}$. The above formula can be used to calculate the load of the bridge and the concrete analysis 
of the calculated load, while the actual situation can be used to effectively judge the demand and form of construction. In the analysis of bridge durability, first of all, scientific situation prediction and calculation methods should be used to ensure that relatively accurate data can be obtained in current research and calculation. Secondly, That the current form of scientific calculation and construction, as well as and adopt advanced methods for construction and control should be learned from. Finally, concrete pouring construction is regarded as a key part of execution design and construction while the quality and level of concrete pouring are integrated to effectively improve the durability of subway.

\section{Conclusion}

To sum up, with the rapid development of our country's economy and society, that strengthening the construction of the city subway ballastless track, making perfect construction plan for laying the whole track bed combined with the comprehensive analysis of the modern citie development, and giving continuous optimization in the implementation process, can ensure the the whole effect of the city subway ballastless track. All the work should be based on the perfect construction plan in the process of application, which should be strictly according to the construction standards and specifications. That strengthening the safety management of the construction site, clearly dividing the specific work contents and duties and improving the overall construction quality and efficiency, can promote the sustainable development of the modern society in our country.

\section{Acknowledgments}

Great acknowledgments to give my colleagues, friends and family for their support and encouragement, especially the technicians, friends and family who worked tirelessly to collect and organize information for me.

\section{References}

1. Sun,L. (2016) Construction Technology Of Double Block Ballastless Track Integrated Roadbed In Railway Tunnel.J.Journal of Railway Engineering,33(12):48-52.

2. Chen,J.G. (2010) Construction Technology Of Double Block Ballastless Track Integrated Roadbed In Railway Tunnel.J.Shanxi Architecture,36(26):301-302.

3. Tian,W.J.(2019)The Construction Method of Integral Track Bed for Double Block Ballastless Track.J.Construction \& Design for Engineering, 14:151-152.

4. Wang, Y.J. (2018) Study on Construction Technology and Application Effect of Ballastless Track Integral Track Bed. Industrial \& Science Tribune, 17(22):55-56.

5. Zhang, T.P .(2017)Study on Construction of Short Sleeper Type Integral Track Bed.Harbin Railway Technology,3:4-6+9.

6. Hu,M.(2018)Construction of Double Block Ballastless Track with Tool Track Method. Management \& Technology of SME, 10:175-176.

7. Yu,P.(2019)The Design of the Integral Track Bed with Bar Sleeper for Urban Rail Transit.Urban Mass Transit,5:171-174.

8. Zhang, M.(2017)Study on the design of new continuous block sleeper for urban rail transit. Railway Engineering, 11:122-125.

9. Zhang,T.(2018)Construction Technology of Large Span Steel Truss Cable-stayed Bridge of Urban Rail Transit. Modern Urban Transit,11:30-33+37.

10. Xu.L.Y.(2017) Construction Technology of Steel Spring Floating Plate Integral Track Bed in Urban Subway Engineering. Building Technology Development,3:58-59. 